\title{
SSRIs, aggression and suicide - a cause for concern or the result of media hype?
}

\author{
Brian E Leonard
}

In recent years, controversy has arisen in the lay press regarding the supposed increase in aggression and suicide in a small minority of patients taking SSRI antidepressants. It has been implied that such adverse effects are a possible result of drug-induced akathisia. ${ }^{1,2}$ Counter arguments have been made that such rare changes in behaviour are a reflection of the underlying pathology of major depression in which agitation, aggression and suicidal ideation and attempts are frequent symptoms. ${ }^{3}$

It has been argued both in the media, and by some protagonists of the suicidal propensity of the SSRIs, that the pharmaceutical industry has knowingly suppressed the information regarding the potential danger of this group of drugs primarily for commercial reasons and that professional organisations and individuals who should be concerned about such dangers are duplicitous in ignoring the evidence. ${ }^{4,6}$

The media in Europe and North America in particular have focussed on a number of bizarre cases in which homicide, followed by suicide of the aggressor who has taken a SSRI (usually fluoxetine), has occurred. ${ }^{31}$ Such dramatic cases have usually been followed by widely publicised court proceedings against the company who manufactured the drug and an outof-court settlement of over a million dollars to the relative usually being the outcome of the case. ${ }^{5}$

In the less emotionally charged area of academic research, depressed patients who had been treated with an SSRI and complained of suicidal thoughts ceased to experience these thoughts when the drug was abruptly withdrawn; the suicidal thoughts returned when the SSRI was introduced. ${ }^{6}$ This is the test-re-test scenario often used in clinical pharmacology to confirm a drug related adverse effect.

\section{Aggressive and suicidal behaviour after SSRIS treatment}

Beside such anecdotal reports, Teicher et $\mathrm{al}^{7}$ reported in detail on the behaviour of six patients with depression, but not apparently suicidal, who developed intense violent suicidal thoughts following two to seven weeks of fluoxetine treatment. An interpretation of the findings of this study was complicated by the high doses of fluoxetine used (up to $80 \mathrm{mg} /$ day), by the multiple psychopathology of the patients and by the co-administration of other psychotropic drugs.

The authors however concluded that $4 / 6$ patients

Brian E Leonard, Emeritus Professor of Pharmacology, National University of Ireland, Galway, Ireland; Visiting Professor, Brain Research Institute, University of Maastricht, The Netherlands. SUBMTTED: DECEMBER 22, 2003 ACCEPTED: FEBRUARY 14, 2004 complained of a sense of inner restlessness which may be interpreted as akathisia, a condition well known to occur in some patients, and estimated to be approximately $21 \%$, on high doses of conventional neuroleptics ${ }^{8-10}$ and other psychotropic drugs such as lithium, ${ }^{11}$ benzodiazepines, ${ }^{12}$ levodopa ${ }^{13}$ and tricyclic antidepressants. ${ }^{14}$

The publication by Teicher et $\mathrm{al}^{7}$ was followed by some other reports in the medical literature of aggressive, suicidal behaviour in some adolescent depressed patients following treatment with a SSRI. ${ }^{15}$ More surprising was a recent report that somewhat similar symptoms occurred in several healthy volunteers who were participating in a clinical study of sertraline and fluoxetine. ${ }^{5}$

The suggestion that antidepressants, including the SSRIs, could initiate aggression and suicidal thoughts is contrary to the experimental and clinical evidence. For example, there are extensive studies in which the use of antidepressants have been shown to result in a reduction in the suicide rate in both men and women. ${ }^{16}$

Jick et $a /^{17}$ estimated the rate and means of suicide among patients taking 10 different commonly prescribed antidepressants. Based on the very large data base of the General Practice Research Data Base of the UK, the authors concluded that the suicide risk was similar for all the antidepressants (these included six different tricyclic antidepressants, fluoxetine, mianserin, trazodone and flupenthixol). They also commented that while the suicide rate was slightly higher in those patients taking fluoxetine, this could be explained by a selection bias rather than by a hidden adverse effect of the drug.

There have been several meta-analyses of controlled trial in which the possible link between fluoxetine and suicide have been assessed. Those studies that report a lack of evidence for an association between fluoxetine and increased suicidal acts or thoughts come from both pharmaceutical company $y^{3,18,19}$ and non-pharmaceutical company sponsored sources. $^{20,21}$

\section{Lack of association between SSRIs and suicide}

Mackay et $a^{22}$ in their observational cohort study of four different SSRIs (fluoxetine, fluvoxamine, sertraline and paroxetine), found no difference between them in the number of successful or unsuccessful suicides. Neither did they differ in terms of these adverse effects in those patients being treated with tricyclic antidepressants. ${ }^{23}$

Quite contrary to the evidence that SSRIs increase suicide risk, there is evidence that both tricyclic antidepressants and fluoxetine actually reduce suicidal ideation and protect against the emergence of suicidal thoughts. ${ }^{18}$ This is supported by the study of Kasper et $a^{24}$ who, in a study of the 
relationship between suicide and depression, concluded that antidepressants such as the SSRIs, due to their central serotonergic action, are of particular benefit to patients at risk from suicide.

Furthermore, Warshaw et $a^{20}$ in their study concluded that while there was no evidence that fluoxetine was associated with increased suicidal attempts, they did find that those depressed patients with more suicidal risk factors at the start of treatment would be more likely to be prescribed fluoxetine than those patients who did not have such risk factors.

This probably accounts for the selection bias reported by Jick et $a .^{17}$

More recently Khan and Brown ${ }^{32}$ in their analysis of 48,277 depressed patients participating in randomised controlled trials against placebo, found that $\mathbf{7 7}$ patients committed suicide. Based on patient exposure years, similar suicide rates were seen among those randomly assigned to a SSRI antidepressant $(0.59 \%)$, a standard antidepressant $(0.76 \%)$ or placebo $(0.45 \%)$. The authors conclude that there is no evidence that there is an overall difference in the suicide risk between antidepressants and placebo treated depressed patients in controlled trials or a difference between SSRI's, other antidepressants or placebo. In another recent study, Hall et $a^{\beta 3}$ examined the association between trends in antidepressant prescribing and suicide rates in Australia for the period 1991 to 2000 . They found that although the overall national suicide rates did not fall significantly over this period, the incidence decreased in older men and women but increased in younger adults. Of particular importance was the finding that the higher the exposure to antidepressants, the greater the decline in the rate of suicide. This association was most apparent in the older age group of depressed patients.These findings concur with those of Carlsten and colleagues $^{34}$ in Sweden who found that the suicide rates declined over the period 1977-1997 and that the rate of decline accelerated after the SSRI's were introduced in 1990. Rihmer ${ }^{35}$ also reported a decline in the suicide rate in Hungary following the introduction of the SSRI's in the early 1990's despite the steep increases in unemployment and in alcohol consumption. Thus the evidence from objective studies on the possible association between the use of SSRI's in depressed patients and increased suicide risk is negative. Indeed, it would appear that the increased presribing of SSRl's produces a quantifiable benefit to mental health.

It is not without interest that the Department of Health in the $\mathrm{UK}^{26}$ has stated that the available evidence does not support an increased risk of suicide following SSRIs but warned that: "Prescribers and patients should be aware that it is general clinical experience that the risk of suicide may increase in the early stages of treatment with any antidepressant". In the US, the Food and Drug Administration ${ }^{26}$ has stated more directly that: "There is no credible evidence of a causal link between the use of antidepressants, including fluoxetine, and suicidality or violent behaviour".

The question now arises whether the anecdotal reports of suicide, homicide and violent behaviour in depressed patients being treated with SSRIs are caused by the drug or the illness. As Walsh and Dinan ${ }^{27}$ noted in their review, a high proportion of patients prescribed the SSRls have made previous suicidal attempts which is why they have been given antidepressants which, unlike the older drugs, are both effective and safe.

Furthermore, many of the anecdotal reports of emergent violent or suicidal acts in which fluoxetine was administered were reported to occur before the antidepressant effect of the drug became apparent. It therefore makes it difficult to argue that a SSRI, or indeed any antidepressant, is the actual cause of the increased suicidal or violent behaviour.

In regard to the increase in irritability and aggression that has been observed in the anecdotal reports from depressed patients on SSRIs, there are several large studies of patients with Alzheimer's disease or vascular dementia in which citalopram or sertraline have been shown to attenuate the symptoms of irritability, restlessness and aggressiveness. ${ }^{28-30}$

Whether akathisia is an idiosyncratic factor that initiates the violent or suicidal attempts in those rare cases in which these behaviours have occurred is unknown.

\section{Conclusion}

In conclusion, the absence of objective data implicating a causal relationship between violence, suicide and the use of SSRIs in depression strongly contradicts the reports that have been highlighted by the media. Such reports can only serve to increase the concerns of the depressed patients and their families regarding antidepressant medication, the outcome of which could be an increase in non-compliance leading inevitably to a risk of increased suicide.

\section{Declaration of Interest: None}

References

1. Creaney W, Murray I, Healy D. Antidepressant induced suicidal ideation. Hum Psychopharmacol 1991; 6: 329-32.

2. Healy DA. A failure to warn. Editorial. Int J Risk \& Safety in Med, 1999; 12: 151-6. 3. Beasley CM, Dornseif BE, Bosomworth JC et al. Fluoxetine and suicide: a metaanalysis of controlled trials of treatment for depression. BMJ 1991; 303: 685-92. 4. Healy D, Creaney W. Antidepressant induced suicidal ideation. Brit Med J 1991; 303: 1058-9.

5. Healy D. Let them eat Prozac. James Lorimer \& Co. Toronto, 2003; 269

6. Rothschild A T, Locke C A. Re-exposure to fluoxetine after serious suicidal attempts by three patients: the role of akathisia. J Clin Psychiat 1991; 52: 491-493.

7. Teicher $M \mathrm{H}$, Glod C, Cole J O. Emergence of intense suicidal preoccupation during fluoxetine treatment. Am J Psychiat 1990; 147: 207-210.

8. Ayd F. A survey of drug induced extrapyramidal reactions. JAMA 1961; 175: 1054-60. 9. Lader M. Psychiatric Disorders In: Avery's Drug Treatment, 4th Edition Eds. Speight TM, Holford NHG. Adis International Ltd. Auckland, New Zealand. 1987;1046-1047. 10. Wojcik J D, Gelenberg A J, LaBrie R A \& Mieske M. Prevalence of tardive dyskinesia in an outpatient population. Compr Psychiat 1980; 21: 370-379.

11. Patterson JF. Amoxapine-induced chorea. South Med J 1983; 76:1077.i

12. Joseph A B, Wroblewski B A. Paradoxical akathisia caused by clonazepam, clorazepate and lorazepam in patients with traumatic encephalopathy and seizure disorders: a subtype of benzodiazepine-induced disinhibition. Behav Neurol 1993; 6: 221-3

13. Riley D E, Lang A E. The spectrum of levodopa-related fluctuations in Parkinson's disease. Neurology, 1993; 43: 1459-1464.

14. Gerber $P E$, Lynd L D. Selective serotonin reuptake inhibitor induced movement disorders. Ann Pharmacotherap. 1998; 32: 692-8.

15. King A, Riddle M A,Chappell P B et al. Emergence of self destructive phenomena in children and adolescents during fluoxetine treatment. J Amer Acad Child Adult Psychiat 1991; 30: 176.

16 Hall WD, Mant A, Mitchell PB et al. Association between antidepressant prescribing and suicide in Australia, 1991-2000: trend analysis. BMJ 2003; 326: 1008-1013.

17. Jick S S, Dean A D, Jick H. Antidepressants and suicide. BMJ 1995: 310: 215-8. 18. Tollefson G D, Fawcett J, Winokur $G$ et al. Evaluation of suicidality during pharmacologic treatment of mood and nonmood disorders. Ann Clin Psychiat 1993; 5 : 209-224.

19. Tollefson GD, Rampey A H, Beasley CM et al. Absence of a relationship between adverse events and suicidality during pharmacotherapy for depression. J Clin Psychopharmacol 1994; 14: 163-169.

20. Warshaw MG, Keller MB. The relationship between fluoxetine use and suicidal behaviour in 654 subjects with anxiety disorders I Clin Psychiat 1996; 57: 158-166 21. Leon A C, Keller M B, Warshaw M G et al. Prospective study of fluoxetine treatment and suicidal behaviour in affectively ill subjects. Am J Psychiat 1999; 156: 195-201. 22. Mackay FJ, Dunn NR, Wilton LV et al. A comparison of fluvoxamine, fluoxetine, sertraline and paroxetine examined by observational cohort studies. Pharmacoepidemiol Drug Safety 1997; 6: 235-246.

23. Edwards JG. Drug choice in depression. Selective serotonin reuptake inhibitors or tricyclic antidepressants? CNS Drugs 1995; 4: 141-159.

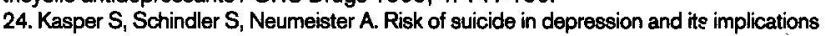
for psychopharmacological treatment. Int Clin Psychopharmacol 1996; 11: 71-79. 
25. Committee on Safety of Medicines. Current problems in pharmacovigilance Selective Serotonin Reuptake Inhibitors (SSRIs) 2000; 26: 11-12.

26. Food and Drug Administration, Review of antidepressants: Psycho Drugs Advisory Committee Report. September, 1991

27. Walsh M-T, Dinan TG, Selective serotonin reuptake inhibitors and violence: a review of the available evidence. Acta Psychiat Scand 2001; 104: 84-91.

28. Nyth A L, Gottfries C G. The clinical efficacy of citalopram in the treatment of emotional disturbance in dementia disorder. Br J Psychiat 1990; 51 (7): 894-901.

29. Pinner $E$, Rich $C L$. Effects of trazodone on aggressive behaviour in 7 patients with organic mental disorders. Am J Psychiat 1988; 145: $1295-1296$.

30. Stanley B, Molcho A, Stanley M et al. Association of aggressive behaviour with altered serotoninergic function in patients who are not suicidal. Am J Psychiat 2000; 157: $609-614$
31. Rosenbaum JF. Clinical trials by media: the Prozac story. In (Ed. Schwartz, HI.) Psychotropic practice under fire. The influence of the Government, the media and special interests on somatic therapies. American Psychiatric Association Press, Washington, DC 1994; 3-27.

32. Khan A,Brown WA. Suicide rates in clinical trials of SSRIs, other antidepresants and placebo:analysis of FDA reports.Am J Psychiat 2003; 160: 790-792.

33. Hall WD, Mant A,Mitchell PB, Rendle VA, Hickie IB,McManus P. Association between antidepresssant prescribing and suicide in Australia, 1991-2000:trend analysis. BM 2003; 326: 1008-17.

34. Carlten A,Waern M,Ekedahl A,Ranstram J. Antidepressant medication and suicide in Sweden. Pharmacoepidemiol. Drug Safety 2001; 10:525-530.

35. Rihmer $Z$. Can better recognition and treatment of depression reduce suicide rates? A brief review. Eur Psychiatry 2001; 16: 406-409.

\section{Guidelines for Authors}

\section{Criteria}

The Journal's aim is to publish original scientific contributions in peychiatry, peychological medicine (including surgery and obstetrics), and related beaic sciences (neurosciences, biological, peychological, and social sciences). Its scope includes any subspecialties of the above, eg. behavioural pharmacology, biological psychiatry, child and adolescent psychiatry, mental handicap, forensic psychiatry, psychotherapies, psychiatry of old age, epidemiology, rehabilitation, psychometrics, substance misuse, sexual studies, linguistics, and the history, philosophy and economics of peychiatry.

The Journal will accept original papers, clinical case reports, brief research reports, review articles, perspective articles, historical papers, editorials, practice reviews (medical audits), letters to the editor and book reviews. Review articles are usually invited. Original data papers receive top priority for speedy publication. Manuscripts should be prepared in accordance with the guidelines of the International Committee of Medical Journal Editors.' All case reports must have the patientes consent belore an article can be published. Format

The page following the title page should carry an Abstract followed by a list of three to 10 Key Words or short phrases drawn, if poesible, from the medical subject headings (MeSH) list of Index Medicus.

The Title, Key Words and Abstract should be chosen to help future literature searchers. The Abstract, up to 150 words for an unstructured or $\mathbf{2 5 0}$ words for the structured abstract, ${ }^{2}$ should state specifically the main purposes, procedures, findings and conclusions of the study, emphasising what is new or important. For original papers, brief research reports, medical audits and review articles, a structured abstract ${ }^{2}$ is required, using the headings Objectives, Methods, Results (Findings for reviow articles) and Conclusions.

Under the Abstract heading of Method, include wherever applicable the study design, setting, patients/participants (selection criteria, description), interventions, observational and analytical methods and main outcome measures. (For review articles specily the methods of literature search and selection). Under the Abstract heading of Results, give the most important specific data together with their statistical significence. References

Timely references should highlight the study's relevance to current research or clinical practice. References to journal articles' ' and to bookste illustrate the 'Vancouver' style,' ie. number references in the order they appear in the text, do not alphabetise. Journal titles should be abbreviated as in Index Medicus. The Uniform requirements for manuscripts submitted to biomedical journals" has two paragraphs on statistical guidelines. These have been explained by Bailar and Mosteller.8 Tables and figures

Figures and graphs should be clear and of good quality, and should be accompanied by relevant data to facilitate redrawing where necessary. All materials sent for publication should be accompanied by a covering lisher online by Gumbridge University Press such material will become the property of the Journal until, and if, publication is refused. Material so referred should not be sent elsewhere for publication. One copy of the manuscript should be retained by the author(s) for reference, and four copies of the manuscript and covering letter, one of these being the original, should be sent to:

The Editor, Irish Journal of Psychological Medicine, 25 Adelaide Street, Dun Laoghaire, Co Dublin, Ireland.

Electronic submissions

Manuscripts may be sent via email to psych (1) medmedia.ie Full postal address, telephone and fax numbers should be included. Where possible tables, figures and text should be included in the same document. There is no need to also submit by post or fax.

Anonymous peer-review

All contributions are peer-reviewed by three anonymous assessors and, where relevant, by the Statistical Editor whom authors may contact for help. Assessments will be sent to the corresponding author usually within six weeks. Where revisions are sought prior to publication, authors are advised to return their revision (in quadruplicate if posting), incorporating any suggestions which they agree would improve their paper. The covering letter should respond to each comment, numbered, of each assessor, indicating where the revision deals with it, or why the authors disagree or cannot incorporate it.

Each assessor will then receive the authors' revision, covering letter and the previous comments of the other assessors. After the assessors' further comments have been received, the senior editors will make the final decision, including priority and time of publication, and the right to style and if necessary shorten material for publication.

Previous publication

Manuscripts are considered with the understanding that they have not been published previously, either in print or electronic format.

Declaration of Interest

In the interest of accountability all financial and material support for the research and the work should be clearly stated.' Authors of original data must take responsibility for the integrity of the data and accuracy of the data analysis. All authors must have full access to all the data in the study.

Acknowledgements

Authors should obtain permission from the individuals named in Acknowledgments, since readers may infer endorsement.

Referencee

1. International Committee of Medical Lournal Editors. Uniform requirements for manuscripts subrnitted to biomedical journals. BMJ 1981; 302: 338-41.

2. Haynes RB. Mulrow CD. Huth EJ, Altman DG, Gardner MJ. More information betracts revisited. Ann Intern Med 1990; 113: 60-76.

3. Ballar JC, Mosteller F. Guidelines for statistical reporting in articles for medical joumals. Ann Intern Med 1988 Feb; 108(2): 266-73.

4. Daly LE, Bourke QJ, MoGilvray J. Interpretation and uses of medical statistics. 4th ad. Oxtord: Blackwell Scientific Publications, 1991: 428-31.

5. Gardner MJ, Altman DG, editors. Statistice with confidence - confidenoe intervals and statistical quidelines. London: British Medical Joumah, 1989: 103-5. INote British Medical Journal here is the publisher of a book, not the journal BMJ.

6. American Payohiatric Association. Diagnostic and statistical manual of mentel 6. American Paychiatric Association. Diagnostic and statistical manual
disorders. Washington DC: American Psychiatric Aseociation, 1887.

7. DeAngelis CD. Fontanarosa PB, Flanagin A. Reporting financial conflicts of 7. DeAngelis CD, Fontanarosa PB, Flanagin A. Reporting financial conflicts of 2001; 286: 89-91.

8. Davidoff $F$, DeAngelis CD, Drazen JM, ot al. Sponsorship, authorship, and . Davidoff F, DeAngelis CD, Drazen JM, 